\title{
Farmed Non-native Coho Salmon in Sanriku Region Affected by Recent Intense Natural Disasters
}

\author{
Kei Sasaki ${ }^{1}$, Tadahide Kurokawa ${ }^{2}$, Koh Hasegawa ${ }^{2}$, and Miwa Yatsuya ${ }^{3}$ \\ ${ }^{I}$ Environment and Fisheries Applied Techniques Research Department, Fisheries Technology Institute, Fisheries \\ Research and Education Agency, Miyako Field station, 4-9-1, Sakiyama, Miyako, Iwate, 027-0097, Japan \\ ${ }^{2}$ Salmon Research Department, Fisheries Resources Institute, Japan Fisheries Research and Education Agency, 2-2 \\ Nakanoshima, Toyohira, Sapporo, Hokkaido 062-0922, Japan \\ ${ }^{3}$ Salmon Research Department, Fisheries Resources Institute, Japan Fisheries Research and Education Agency, \\ Miyako Field Station, 4-9-1, Sakiyama, Miyako, Iwate, 027-0097, Japan
}

Keywords: escaped farmed salmon, Oncorhynchus kisutch, masu salmon, hybridization

Coho salmon farming is an economically important activity in the Sanriku region, which has recently experienced unprecedented natural disasters, including the Great East Japan Earthquake (GEJE), and the direct impacts of large typhoons. Each of these events was associated with a large number of farmed coho salmon escaping from hatcheries or net pens. As a result, there is considerable concern about the impact of these escapes on the ecosystem, especially on native masu salmon which occupy a similar ecological niche to coho salmon. Furthermore, coho salmon can hybridize with masu salmon (Ito et al. 2006), and hybridization is widely considered to have deleterious effects on native salmonid populations (Allendorf et al. 2001; Muhlfeld et al. 2009).

At the time of the GEJE in March 2011, five million farmed adult (1 yr+) coho salmon escaped into the ocean off the Sanriku coast, and in the fall of the same year, they migrated up several rivers in the region (Fig. 1). In addition to the presence of mature individuals among the returning coho salmon, spawning behavior was also observed. We, therefore, conducted a survey and performed genetic analyses to test for the presence of hybrids among sea-run masu salmon caught along the coast. The results revealed that there was no evidence of hybridization and that there has been no decrease in the number of masu salmon along the Sanriku coast since the GEJE.
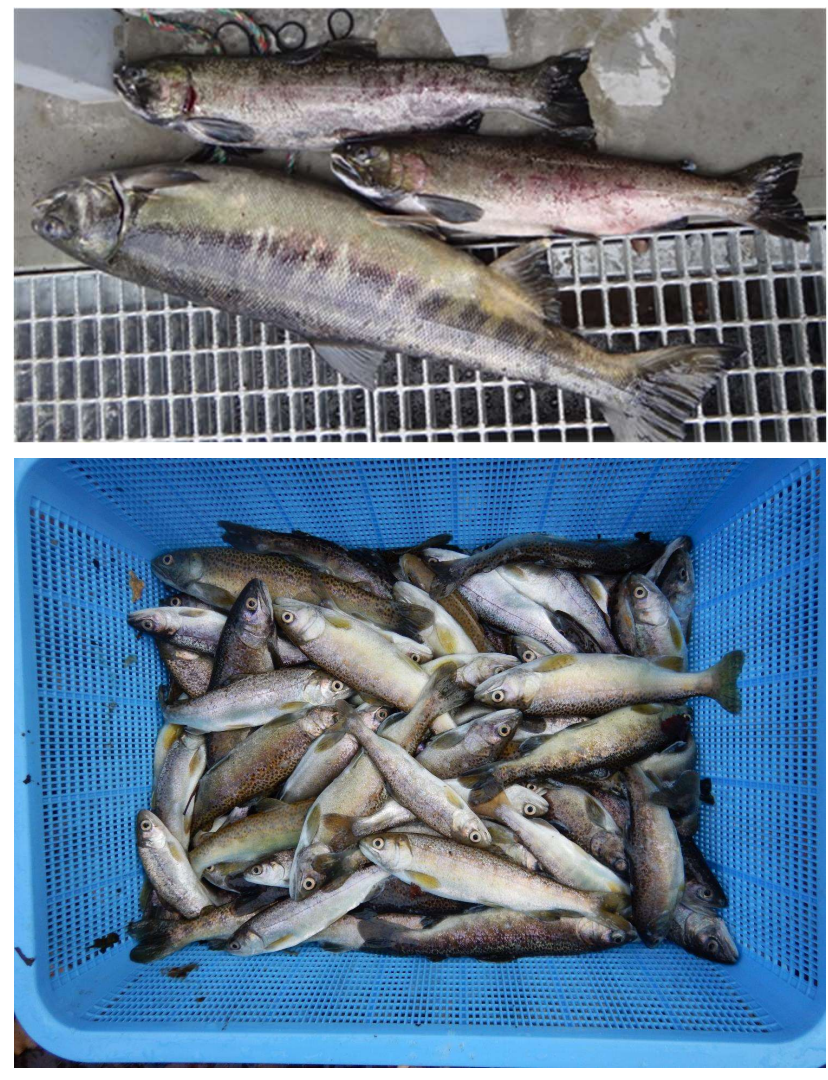

Fig. 1. Two farmed adult coho salmon (top) and a chum salmon (larger fish at bottom) that had migrated upstream in rivers of the Sanriku region in October 2011.

Fig. 2. Farmed juvenile coho salmon that escaped into a natural river in Japan. 
In August 2016, due to flooding caused by a typhoon, 500 thousand farmed juvenile $(0 \mathrm{yr}+)$ coho salmon escaped into a river in the Sanriku region (Fig. 2). A monitoring survey of population density in the river revealed that the number of coho salmon decreased over time. Since smolts were observed, one of the reasons for the decrease appeared to be due to seaward migration, but no individuals have returned to spawn in the river. Therefore, escaped coho salmon may be unable to establish viable populations in the Sanriku region.

These findings imply that the genetic impact of coho salmon on masu salmon population may not be serious. However, the impact of the escaped coho salmon on the ecosystem is still unclear. Non-native salmonids can change the population and community structure of native species, including salmonids, not only through hybridization but also through predation and interspecific competition. In the Sanriku region, Age-2 coho salmon that have managed to escape from net-pens are caught every year, and escapement from fish farms into rivers also frequently occurs. It has been reported that continued introduction increases the likelihood of establishment (Fausch 2007). Given that the quantities of farmed salmon will increase in the future, we need to be aware of two things. First, in ordinary times, advances in techniques for preventing farmed salmon from escaping are necessary. Second, as a pre-emptive measure for mitigating against the risk of a large-scale disaster, a monitoring system for assessing the impact of escapement on the natural environment should be developed.

\section{REFERENCES}

Allendorf, F.W., R.F. Leary, P. Spruell, and J.K. Wenburg. 2001. The problems with hybrids: setting conservation guidelines. Trends Ecol. Evol. 16: 613-622.

Fausch, K.D. 2007. Introduction, establishment and effects of non-native salmonids: considering the risk of rainbow trout invasion in the United Kingdom. J. Fish Biol. 71: 1-32.

Ito, D., A. Fujiwara, and S. Abe. 2006. Hybrid inviability and chromosome abnormality in salmonid fish. J. Anim. Genet. 34: 65-70. (In Japanese)

Muhlfeld, C.C., S.T. Kalinowski, T.E. McMahon, M.L. Taper, S. Painter, R.F. Leary, and F.W. Allendorf. 2009. Hybridization rapidly reduces fitness of a native trout in the wild. Biol. Lett. 5: 328-331. 